\title{
BMJ Open Association between body mass index and obesity-related cancer risk in men and women with type 2 diabetes in primary care in the Netherlands: a cohort study (ZODIAC-56)
}

Steven H Hendriks, ${ }^{1}$ Dennis Schrijnders, ${ }^{1,2}$ Kornelis JJ van Hateren, ${ }^{2}$ Klaas H Groenier, ${ }^{1,3}$ Sabine Siesling, ${ }^{4,5}$ Angela H E M Maas, ${ }^{6}$ Gijs W D Landman, ${ }^{2,7}$ Henk J G Bilo, ${ }^{1,8,9}$ N Kleefstra ${ }^{2,8}$

To cite: Hendriks SH,

Schrijnders D, van Hateren KJJ, et al. Association between body mass index and obesity-related cancer risk in men and women with type 2 diabetes in primary care in the Netherlands: a cohort study (ZODIAC-56). BMJ Open 2018;8:e018859. doi:10.1136/ bmjopen-2017-018859

- Prepublication history for this paper is available online. To view these files, please visit the journal online (http://dx.doi. org/10.1136/bmjopen-2017018859).

Received 25 July 2017 Revised 29 November 2017 Accepted 7 December 2017

Check for updates

For numbered affiliations see end of article.

Correspondence to Dr Steven H Hendriks; shhendriks@outlook.com

\section{ABSTRACT}

Objective To investigate the relationship between body mass index (BMI) and obesity-related cancers in men and women with type 2 diabetes (T2D).

Design Observational cohort study.

Setting Primary care.

Participants A total of 52044 patients with T2D who participated in the ZODIAC (Zwolle Outpatient Diabetes project Integrating Available Care) study between 1998 and 2012 was included (49\% women). A dataset of these patients was linked to available information of the Netherlands Cancer Registry to obtain data on cancer incidents.

Primary outcome measures Analyses were performed for the total group of obesity-related cancers and for non-sex-specific and sex-specific obesity-related cancers (in men: advanced prostate cancer, in women: ovarian, endometrial and postmenopausal breast cancer). Results The median follow-up period in all analyses was $3.1(1.7-5.0)$ years in men and $3.1(1.7-5.1)$ in women. During follow-up, 689 men and 914 women were diagnosed with an obesity-related cancer. In men, BMI was associated with a higher risk of the total group of obesityrelated cancers and non-sex-specific obesity-related cancers (HR (per $5 \mathrm{~kg} / \mathrm{m}^{2}$ increase) 1.12 (95\% Cl 1.02 to 1.23) and $\mathrm{HR} 1.18$ (95\% $\mathrm{Cl} 1.06$ to 1.31)). No association was found with prostate cancer. In women, an association between $\mathrm{BMI}$ and all obesity-related cancers combined and sex-specific obesity-related cancers was present (HR 1.15 (95\% Cl 1.08 to 1.22) and HR $1.22(95 \% \mathrm{Cl} 1.14$ to 1.32)). No association with non-sex-specific cancers was found in women.

Conclusions $\mathrm{BMI}$ is associated with obesity-related cancers in men with $\mathrm{T} 2 \mathrm{D}$, except with advanced prostate cancer. The results of this study provide reason to reconsider the classification of advanced prostate cancer as an obesity-related cancer, at least in T2D. In women, BMI is associated with the total group of obesity-related cancers and with sex-specific obesityrelated cancers.
Strengths and limitations of this study

- This is the first study investigating sex differences in relation between body mass index (BMI) and obesityrelated cancer in a large cohort of patients with type 2 diabetes (T2D) who are treated in primary care.

- A dataset of 71634 patients with T2D was linked to the Netherlands Cancer Registry to obtain data on cancer incidents and finally 52044 patients were included in the present study.

- Data on BMI were available for $91 \%$ of all included patients.

- The grouping of obesity-related cancers could be discussed.

- The median follow-up time was relatively short for cancer epidemiology.

\section{INTRODUCTION}

Type 2 diabetes (T2D) is associated with an increased risk for cardiovascular morbidity and mortality. ${ }^{12}$ Furthermore, T2D is also related to a higher cancer risk. ${ }^{34}$ This increased cancer risk appears to be site-specific; a higher risk for liver, pancreas, endometrial, colorectal, breast and bladder cancer has been reported in patients with T2D. ${ }^{3}$ Whether this increased risk is directly related to T2D, caused by longer periods of hyperglycaemia and/or elevated insulin levels, or indirectly, due to common risk factors like obesity, is not clear. ${ }^{3}$

According to the World Cancer Research Fund, being overweight or obese is related to an increased incidence of oesophageal, stomach (cardia), colorectal, liver, gallbladder, pancreatic and kidney cancer in both sexes in the general population. Furthermore, being overweight or obese is related to an increased incidence of ovarian, 


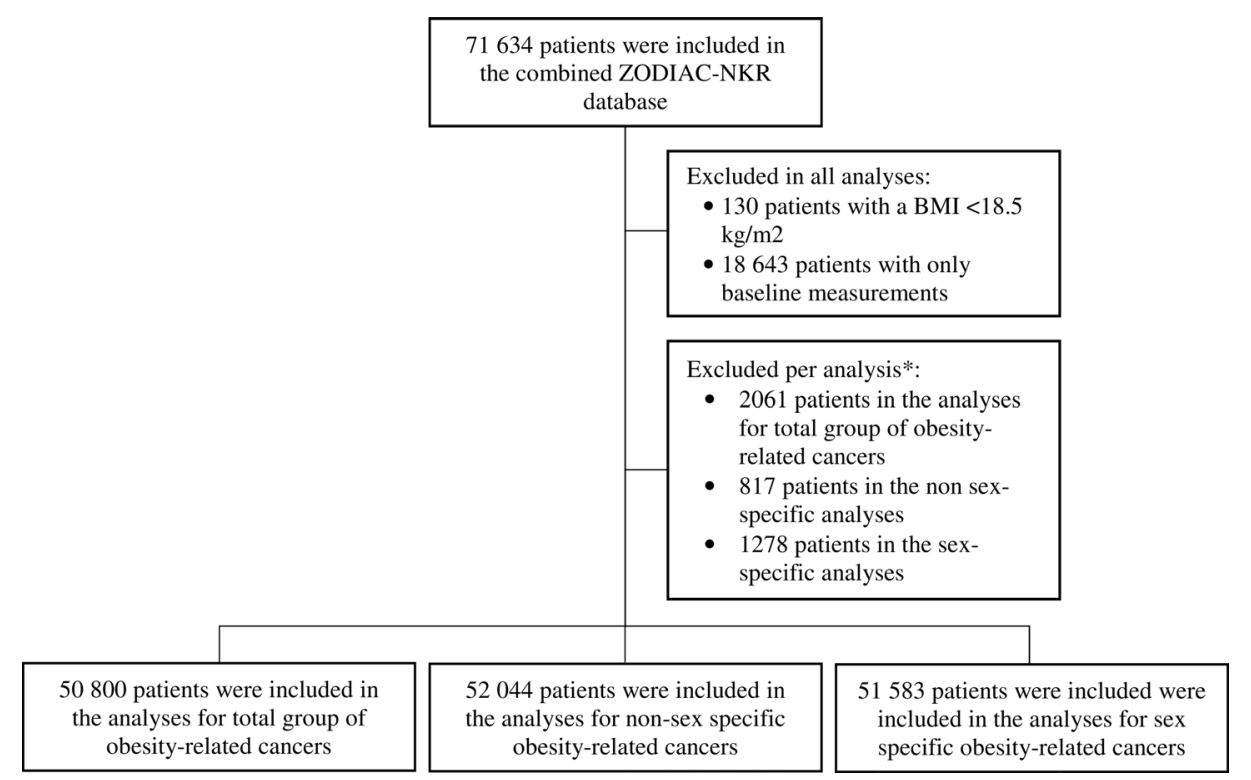

Figure 1 Flow chart of inclusion. *For the analyses of the total group of obesity-related cancers, patients diagnosed with a non-sex-specific or sex-specific obesity-related cancer before entering the ZODIAC study were excluded. For the non-sexspecific analysis, only patients with a non-sex-specific cancer before entering the ZODIAC study were excluded. For the sexspecific cancer analysis, only patients with a sex-specific cancer before entering the ZODIAC study were excluded. BMI, body mass index; NKR, the Netherlands Cancer Registry; ZODIAC, Zwolle Outpatient Diabetes project Integrating Available Care.

endometrial and postmenopausal breast cancer in women and to advanced prostate cancer in men. ${ }^{5}$

Whether there is an association between body mass index (BMI) and excess risk of developing obesity-related cancers in patients with T2D is unclear. One previous study did not find an association between BMI and obesity-related cancers in T2D. ${ }^{6}$ Another study investigated this association with colon cancer and found only a significant relationship in patients who suffered from obesity for a total duration of 4 years or more. ${ }^{7}$

Even more unclear is whether there is a sex difference in the association between BMI and obesity-related cancers in patients with T2D. A large prospective study from Sweden reported an association between being overweight and obesity with all cancers and gastrointestinal cancers in men. However, in women only an association with obesity and both cancer groups was found. ${ }^{8}$ This could indicate that the threshold for BMI to act as a risk factor for obesity-related cancer is lower in men compared with women with T2D. Therefore, the aim of the present study was to investigate the relationship between BMI and obesity-related cancers in men and women with T2D and specifically non-sex-specific and sex-specific obesity-related cancers.

\section{MATERIALS AND METHODS \\ Study group}

The study population consisted of patients who were included in the Zwolle Outpatient Diabetes project Integrating Available Care (ZODIAC) study. This project started in 1998 and was part of a study at that time that primarily investigated the effects of shared care in patients with T2D treated in primary care in the Zwolle region of the Netherlands. ${ }^{9}$ This shared care initiative became the standard care for the Zwolle region in 2002 and expanded to other regions in the Netherlands in the years thereafter. In these regions, general practitioners (GPs) provide data on an annual basis to the Diabetes Centre for benchmark and research purposes. Patients with only T2D treated in primary care are included in the ZODIAC project. The diagnosis of T2D was based on the guidelines of the Dutch College of General Practitioners (twice a fasting plasma glucose level $\geq 7 \mathrm{mmol} / \mathrm{L}$ or once a non-fasting plasma glucose level $\geq 11.1 \mathrm{mmol} / \mathrm{L}$ accompanied by symptoms of hyperglycaemia). Patients with a very short life expectancy or insufficient cognitive capabilities are excluded from participation. At the start in 1998, 53 GPs participated in this project, and this number increased to more than 700 GPs in 2012.

For the current study, available information on clinical variables from patients participating for at least 1 year in the ZODIAC project between 1998 and 2012 was linked to available information of the Netherlands Cancer Registry (NKR) to obtain data on cancer incidents in the years between 1989 and 2012. Information from the NKR in the period before 1998 was used to exclude patients who were diagnosed with an obesity-related cancer before entering the ZODIAC study. The NKR started in 1989 and records all malignancies based on notification by the National Pathology Archive and hospital discharge registries in the Netherlands. Basal cell carcinoma of the skin, carcinoma in situ of the cervix, myelodysplastic syndrome, myeloproliferative disorders are not registered in the NCR database. Data on patient characteristics, tumour type and grade, and treatment 


\begin{tabular}{|c|c|c|c|}
\hline Variable & Men & Women & P value* \\
\hline $\mathrm{N}$ & 25811 (49.2) & 24989 (50.8) & \\
\hline Age (years) & $64.0( \pm 11.2)$ & $66.6( \pm 12.1)$ & $<0.001$ \\
\hline $\begin{array}{l}\text { Diabetes duration } \\
\text { (years) }\end{array}$ & $2.5(0.7-5.8)$ & $2.8(0.8-6.3)$ & $<0.001$ \\
\hline $\mathrm{HbA1c}(\mathrm{mmol} / \mathrm{mol})$ & $49(43-55)$ & $49(43-54)$ & 0.091 \\
\hline Creatinine $(\mu \mathrm{mol} / \mathrm{L})$ & 83 (73-95) & 68 (59-79) & $<0.001$ \\
\hline Smoking (yes) & 8029 (31) & 4857 (19) & $<0.001$ \\
\hline BMI $\left(\mathrm{kg} / \mathrm{m}^{2}\right)$ & $29.2(4.6)$ & $30.4(5.7)$ & $<0.001$ \\
\hline $\begin{array}{l}\text { Use of metformin } \\
\text { (yes) }\end{array}$ & $14813(57)$ & 13539 (54) & $<0.001$ \\
\hline $\begin{array}{l}\text { Use of } \\
\text { SU derivatives } \\
\text { (yes) }\end{array}$ & 7977 (31) & 7638 (31) & 0.408 \\
\hline Use of insulin (yes) & 2135 (8) & $2512(10)$ & $<0.001$ \\
\hline
\end{tabular}

Values are depicted as $\mathrm{n}(\%)$, mean $( \pm \mathrm{SD})$ or median (IQR). Continuous data were analysed using independent t-tests or the Mann-Whitney $\mathrm{U}$ test. Categorical variables were analysed using $\chi^{2}$ tests.

${ }^{*} \mathrm{P}$ value for the difference between men and women.

$\mathrm{BMI}$, body mass index; SU, sulfonylurea.

are collected by specially trained data managers directly from the patients' files in all hospitals in the Netherlands. The linking was performed by a trusted third party using postal code, full name, date of birth and sex. The NKR expects that the number of false-positive and the number false-negative for the ZODIAC-NKR linkage is both under $1 \%$. The combined ZODIAC-NKR database contains 71634 patients, of which 10717 (15\%) were diagnosed with cancer.

\section{Data collection}

For the current study, a database was constructed which consisted of both the variables of the ZODIAC project and the variables of the NKR. The demographic and clinical data which were used in the present study were collected as part of ZODIAC project and included: sex, age, diabetes duration, HbAlc, serum creatinine, BMI, smoking status and the use of metformin, sulfonylurea (SU) derivatives and insulin. Information on smoking was collected during the check-up of the patient by the GP or practice nurse as part of the ZODIAC project whereby smoking was documented as yes or no. No data concerning previous smoking were available. Baseline was defined as the first year that a patient was included in the ZODIAC project. Cancer characteristics provided and collected by the NKR were cancer origin, incidence date, tumour, node, metastases (TNM) stage, morphology and type of therapy.

\section{Study procedure}

The association between BMI and obesity-related cancer was investigated for three groups: total group of obesity-related cancers, non-sex-specific obesity-related cancers and sex-specific obesity-related cancers. The non-sex-specific cancer group consisted of gastric-cardia (International Classification of Diseases (ICD) C16.0), colorectal (ICD C18, 19, 20), liver (ICD C22), gall bladder (ICD C23), pancreas (ICD C25) and kidney cancer (ICD C64) and adenocarcinoma of the oesophagus (ICD C15.5+ morphological codes 8140 or 8560). In men, the sex-specific cancer group was formed by advanced prostate cancers only (ICD C61 +TNM 3 or 4 or Gleason score $>7$ ) (further referred to as prostate cancer). In women, the sex-specific cancer group consisted of ovarian

Table 2 Regression analyses for all obesity-related cancers in men and women*

\begin{tabular}{|c|c|c|c|c|}
\hline \multirow[b]{2}{*}{ Variable } & \multicolumn{2}{|l|}{ Men } & \multicolumn{2}{|l|}{ Women } \\
\hline & $\begin{array}{l}\text { Crude } \\
\text { HR }(95 \% \mathrm{Cl})\end{array}$ & $\begin{array}{l}\text { Adjusted } \\
\text { HR ( } 95 \% \mathrm{Cl})\end{array}$ & $\begin{array}{l}\text { Crude } \\
\text { HR }(95 \% \mathrm{Cl})\end{array}$ & $\begin{array}{l}\text { Adjusted } \\
\text { HR }(95 \% \text { CI) }\end{array}$ \\
\hline BMI (per $\left.5 \mathrm{~kg} / \mathrm{m}^{2}\right)$ & 1.11 (1.01 to 1.22$)$ & 1.12 (1.02 to 1.23$)$ & 1.14 (1.07 to 1.21$)$ & 1.15 (1.08 to 1.22$)$ \\
\hline Diabetes duration (years) & & 0.99 (0.97 to 1.01$)$ & & 0.99 (0.97 to 1.00$)$ \\
\hline $\mathrm{HbA1c}(\mathrm{mmol} / \mathrm{mol})$ & & 1.00 (0.99 to 1.01$)$ & & 1.00 (0.99 to 1.00$)$ \\
\hline Creatinine ( $\mu \mathrm{mol} / \mathrm{L})$ & & 1.00 (0.99 to 1.00$)$ & & 1.00 (1.00 to 1.00$)$ \\
\hline Use of metformin & & 0.94 (0.80 to 1.10$)$ & & 0.98 (0.85 to 1.22$)$ \\
\hline Use of SU derivatives & & 1.16 (0.98 to 1.37$)$ & & $1.03(0.88$ to 1.19$)$ \\
\hline Use of insulin & & 1.14 (0.84 to 1.54$)$ & & 1.09 (0.85 to 1.40$)$ \\
\hline Smoking & & 1.02 (0.86 to 1.22$)$ & & 1.11 (0.93 to 1.33 ) \\
\hline
\end{tabular}

${ }^{*}$ Gastric- cardia (ICD C16.0) (events in men: 18, events in women: 3), colorectal (ICD C18, 19, 20) (events in men: 330, events in women: 247), liver (ICD C22) (events in men: 15, events in women: 8), gall bladder (ICD C23) (events in men: 2, events in women: 7), pancreas (ICD C25) (events in men: 59, events in women: 41), kidney cancer (ICD C64) (events in men: 60, events in women: 38) and adenocarcinoma of the oesophagus (ICD C15.5+ morphological codes 8140 or 8560 ) (events in men: 46, events in women: 7). In men supplemented with advanced prostate cancers (C61 +TNM 3 or 4 or Gleason score $>7$ ) (events in men: 159). In women supplemented with ovarian (ICD C56) (events in women: 39), endometrial (ICD C54.1) (events in women: 117) and postmenopausal breast cancer (ICD C50 and age $\geq 55$ years) (events in women: 407).

BMI, body mass index; ICD, International Classification of Diseases; SU, sulfonylurea; TNM, tumour, node and metastases. 


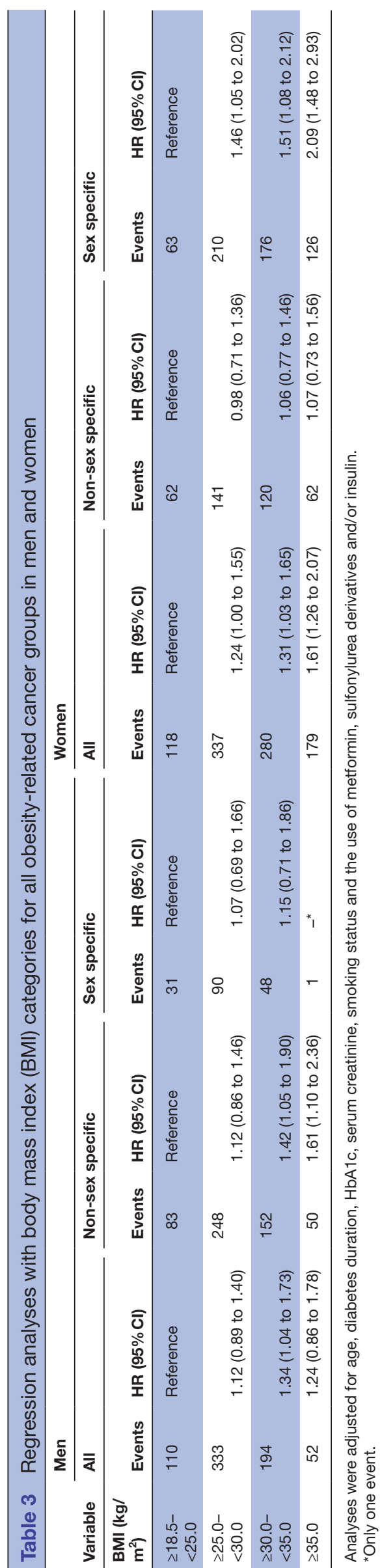

(ICD C56), endometrial (ICD C54.1) and postmenopausal breast cancer (ICD C50) (further referred to as ovarian, endometrial and breast cancer). The total group of obesity-related cancers consisted of non-sex-specific cancers and prostate cancer in men and of non-sex-specific cancers and ovarian, endometrial and breast cancer in women. Postmenopausal breast cancer was in the present study defined as breast cancer in women $\geq 55$ years of age. ${ }^{10}$ All included cancer cases were histologically confirmed by a pathologist.

Patients with a BMI $<18.5 \mathrm{~kg} / \mathrm{m}^{2}$ were excluded in all analyses, as undiagnosed cancer may lead to becoming underweight $(\mathrm{n}=130(0.2 \%))$. Furthermore, patients were excluded if they had only baseline data recorded (only one check-up by their care provider) $(\mathrm{n}=18.643(26.0 \%))$. For the analyses of the total group of obesity-related cancers, patients diagnosed with a non-sex-specific or sex-specific obesity-related cancer before entering the ZODIAC study were excluded $(\mathrm{n}=2061(2.9 \%))$. For the non-sex-specific analysis, only patients with a non-sex-specific cancer before entering the ZODIAC study were excluded $(n=817$ $(1.1 \%))$. For the sex-specific cancer analysis, only patients with a sex-specific cancer before entering the ZODIAC study were excluded ( $\mathrm{n}=1278(1.8 \%)$ ) (figure 1).

Clinical endpoint in all analyses was the first obesity-related cancer after baseline. Patients were not censored if they were diagnosed with a non-obesity-related cancer during follow-up. The end of follow-up for patients who were not diagnosed with cancer was based on the last check-up by their GP.

\section{Statistical analyses}

Statistical analyses were performed using SPSS V.23 for Windows (SPSS, Chicago, Illinois, USA) and Stata V.14.0 for Windows. Multiple imputation analysis was performed for missing data on the independent variables, assuming that data were missing at random or completely at random. All variables of model 2 were included in the imputation model and the fully conditional specification model in SPSS was used to predict the missing data. Ten imputated datasets were created and the pooled results are presented. Baseline data are expressed as mean with SD or median with IQR for normally distributed and non-normally distributed data, respectively. Categorical variables are described in numbers and percentages. Normal distribution was assessed on the basis of histograms and $\mathrm{Q}-\mathrm{Q}$ plots. A two-sided $\mathrm{P}<0.05$ was considered significant. Cox proportional hazard analyses were used to investigate the association between BMI as a continuous and categorical variable and obesity-related cancers in men and women with T2D, separately. HRs refer to a BMI increase of $5 \mathrm{~kg} / \mathrm{m}^{2}$ in the analyses for BMI as a continuous variable. For the analyses of BMI as a categorical variable, four BMI categories were used $\left(\geq 18.5-<25.0 \mathrm{~kg} / \mathrm{m}^{2}\right.$, $\left.\geq 25.0-<30.0 \mathrm{~kg} / \mathrm{m}^{2}, \quad \geq 30.0-<35.0 \mathrm{~kg} / \mathrm{m}^{2}, \quad \geq 35.0 \mathrm{~kg} / \mathrm{m}^{2}\right)$. The lowest category was used as reference category. Age was used as the time scale in all analyses, because the risk of cancer is not proportional with age. Patients 
Table 4 Regression analyses for non-sex-specific obesity-related cancers in men and women*

\begin{tabular}{|c|c|c|c|c|}
\hline \multirow[b]{2}{*}{ Variable } & \multicolumn{2}{|l|}{ Men } & \multicolumn{2}{|l|}{ Women } \\
\hline & $\begin{array}{l}\text { Crude } \\
\text { HR (95\% CI) }\end{array}$ & $\begin{array}{l}\text { Adjusted } \\
\text { HR }(95 \% \mathrm{Cl})\end{array}$ & $\begin{array}{l}\text { Crude } \\
\text { HR }(95 \% \mathrm{Cl})\end{array}$ & $\begin{array}{l}\text { Adjusted } \\
\text { HR }(95 \% \text { Cl) }\end{array}$ \\
\hline Diabetes duration (years) & & $1.00(0.97$ to 1.02$)$ & & $0.98(0.96$ to 1.01$)$ \\
\hline $\mathrm{HbA} 1 \mathrm{c}(\mathrm{mmol} / \mathrm{mol})$ & & $1.00(0.99$ to 1.01$)$ & & $1.00(0.99$ to 1.01$)$ \\
\hline Use of SU derivatives & & $1.07(0.88$ to 1.30$)$ & & $1.15(0.92$ to 1.44$)$ \\
\hline Use of insulin & & $1.04(0.73$ to 1.49$)$ & & $1.19(0.82$ to 1.74$)$ \\
\hline Smoking & & $1.09(0.90$ to 1.33$)$ & & $1.33(1.01$ to 1.76$)$ \\
\hline
\end{tabular}

*Gastriccardia (ICD C16.0) (events in men: 19, events in women: 3), colorectal (ICD C18, 19, 20) (events in men: 330, events in women: 270), liver (ICD C22) (events in men: 15, events in women: 8), gall bladder (ICD C23) (events in men: 2, events in women: 8), pancreas (ICD C25) (events in men: 59, events in women: 44), kidney cancer (ICD C64) (events in men: 62, events in women: 45) and adenocarcinoma of the oesophagus (ICD C15.5+ morphological codes 8140 or 8560 ) (events in men: 46, events in women: 7).

BMI, body mass index; ICD, International Classification of Diseases; SU, sulfonylurea.

entered the analysis at their baseline age and exited at their event/censoring age. Two models were used: an age-adjusted model (model 1) and a model additionally adjusted for diabetes duration, HbAlc, serum creatinine, smoking status and the use of metformin, SU derivatives and/or insulin (model 2). Furthermore, the analyses for model 2 were stratified according to the year of inclusion in the ZODIAC cohort. The assumption of proportional hazards for baseline predictors was investigated by visual inspection of the Schoenfeld residuals.

\section{RESULTS}

Total group of obesity-related cancers

Baseline results for the men and women who are included in the analyses for the total group obesity-related cancers are described in table 1 . In these analyses, 25811 men and 24989 women were included. Mean age was 64.0 (SD
$11.2)$ years in men and 66.6 (12.1) years in women. The median diabetes duration was higher in women. More men than women were current smokers and men had a lower BMI than women. A higher percentage of men used metformin whereas insulin use was more frequent in women. $30.4 \%$ of the patients did not use metformin, SU derivatives or insulin. These patients were on dietary interventions or other diabetes medication. The median follow-up period for these patients was $3.1(1.7-5.0)$ years in men and 3.1 (1.7-5.1) in women. During follow-up, $689(2.7 \%)$ men and 914 women $(3.7 \%)$ were diagnosed with an obesity-related cancer.

The results of the association between BMI as a continuous variable and the total group of obesity-related cancers are described in table 2 for men and women, separately. In both men and women, BMI was associated with a higher risk of obesity-related cancer in the

Table 5 Regression analyses for sex-specific obesity-related cancers in men and women*

\begin{tabular}{|c|c|c|c|c|}
\hline & Men & & Women & \\
\hline Variable & $\begin{array}{l}\text { Crude } \\
\text { HR (95\% Cl) }\end{array}$ & $\begin{array}{l}\text { Adjusted } \\
\text { HR }(95 \% \mathrm{Cl})\end{array}$ & $\begin{array}{l}\text { Crude } \\
\text { HR (95\% Cl) }\end{array}$ & $\begin{array}{l}\text { Adjusted } \\
\text { HR ( } 95 \% \text { Cl) }\end{array}$ \\
\hline BMI (per $\left.5 \mathrm{~kg} / \mathrm{m}^{2}\right)$ & $0.92(0.74$ to 1.15$)$ & $0.93(0.75$ to 1.16$)$ & $1.22(1.13$ to 1.31$)$ & 1.22 (1.14 to 1.32$)$ \\
\hline Diabetes duration (years) & & 0.98 (0.95 to 1.02$)$ & & 0.98 (0.96 to 1.01$)$ \\
\hline $\mathrm{HbA1c}(\mathrm{mmol} / \mathrm{mol})$ & & 0.99 (0.98 to 1.01$)$ & & 1.00 (0.99 to 1.01$)$ \\
\hline Creatinine $(\mu \mathrm{mol} / \mathrm{L})$ & & 1.00 (0.99 to 1.00$)$ & & 1.00 (1.00 to 1.00$)$ \\
\hline Use of metformin & & 1.17 (0.85 to 1.61$)$ & & 0.86 (0.73 to 1.03$)$ \\
\hline Use of SU derivatives & & 1.50 (1.07 to 2.09 ) & & 0.93 (0.77 to 1.13$)$ \\
\hline Use of insulin & & 1.34 (0.74 to 2.42$)$ & & 1.05 (0.76 to 1.44$)$ \\
\hline Smoking & & 0.81 (0.55 to 1.19$)$ & & 1.00 (0.79 to 1.27$)$ \\
\hline
\end{tabular}

*In men supplemented with advanced prostate cancers (C61 +TNM 3 or 4 or Gleason score >7) (events in men: 170). In women supplemented with ovarian (ICD C56) (events in women: 39), endometrial (ICD C54.1) (events in women: 119) and postmenopausal breast cancer (ICD C50 and age $\geq 55$ years) (events in women: 417 ).

BMI, body mass index; ICD, International Classification of Diseases; SU, sulfonylurea; TNM, tumour, node and metastases. 
age and fully adjusted analyses (in men: HR $1.11(95 \%$ CI 1.01 to 1.22 ) and HR 1.12 (95\% CI 1.02 to 1.23 ), in women: HR 1.14 (95\% CI 1.07 to 1.21 ) and HR 1.15 (95\% CI 1.08 to 1.22)). Analysis of BMI as a categorical variable showed that in men a BMI of $30.0-35.0 \mathrm{~kg} / \mathrm{m}^{2}$ was associated with a higher risk of obesity-related cancer compared with the reference group. In women, a BMI of $30.0-35.0 \mathrm{~kg} / \mathrm{m}^{2}$ and a BMI $\geq 35.0 \mathrm{~kg} / \mathrm{m}^{2}$ were both associated with a higher risk of obesity-related cancer compared with the reference group (table 3 ).

\section{Non-sex-specific obesity-related cancers}

In the analyses for non-sex-specific obesity-related cancers, 25945 men and 26099 women were included. Baseline results for these patients did not significantly differ from the baseline results described in table 1 (data not shown). The median follow-up period was $3.1(1.7-5.0)$ years in men and $3.1(1.7-5.1)$ in women. During follow-up, 533 $(2.1 \%)$ men and 385 (1.5\%) women were diagnosed with a non-sex-specific obesity-related cancer.

In men, BMI was associated with a higher risk of non-sex-specific obesity-related cancer in the age and fully adjusted analyses (HR 1.17 (95\% CI 1.05 to 1.30 ) and HR 1.18 (95\% CI 1.06 to 1.31)) (table 4). In the categorical analyses, a BMI of $30.0-35.0 \mathrm{~kg} / \mathrm{m}^{2}$ and a $\mathrm{BMI} \geq 35.0 \mathrm{~kg} / \mathrm{m}^{2}$ were also associated with a higher risk of non-sex-specific obesity-related cancer in men (table 3). In women, no significant associations between BMI as a continuous or categorical variable and non-sex-specific obesity-related cancers were found.

\section{Sex-specific obesity-related cancers}

In the analyses for sex-specific obesity-related cancers, 26226 men and 25357 women were included. Baseline results for these patients did not significantly differ from the baseline results described in table 1 (data not shown). The median follow-up period for these patients was 3.1 (1.7-5.0) years in men and 3.1 (1.7-5.1) in women. During follow-up, $170(0.7 \%)$ men and $575(2.3 \%)$ women were diagnosed with a sex-specific obesity-related cancer.

In men, no significant associations between BMI as a continuous or categorical variable and prostate cancer was found (tables 2 and 5). In women, BMI was associated with a higher risk of ovarian, endometrial and breast cancer in the age and fully adjusted analyses (HR 1.22 (95\% CI 1.13 to 1.31) and HR 1.22 (95\% CI 1.14 to 1.32$)$ ). In the categorical analyses, a BMI of $25.0-30.0 \mathrm{~kg} / \mathrm{m}^{2}$, a BMI of $30.0-35.0 \mathrm{~kg} / \mathrm{m}^{2}$ and a BMI $\geq 35.0 \mathrm{~kg} / \mathrm{m}^{2}$ were associated with a higher risk of ovarian, endometrial and breast cancer in women (table 2).

\section{DISCUSSION}

The results of the present study showed that BMI was associated with the total group of obesity-related cancers in both men and women with T2D. Important differences between men and women were found; BMI was associated with non-sex-specific obesity-related cancers in men, but not in women. Results concerning the sex-specific cancers showed that BMI was associated with ovarian, endometrial and postmenopausal breast cancer in women. No association between BMI and advanced prostate cancer was found in men.

This is the first study which describes the association between BMI and the total group of obesity-related cancers in a large cohort of men and women with T2D. A study from Japan could not find an association between BMI and all obesity-related cancers. ${ }^{6}$ However, this was a study that included 2334 patients of whom only 35 patients developed cancer during follow-up. ${ }^{6}$

The absence of a significant association between BMI and non-sex-specific obesity-related cancers in women may indicate that BMI (in contrast to men) is not a risk factor for this group of cancers. Only one study has previously described sex differences in the association between BMI and non-sex-specific obesity-related cancers in patients with T2D. ${ }^{8}$ A study from Sweden found that being overweight or obese was associated with a higher risk of gastrointestinal cancers in men, whereas in women only obesity but not overweight was found to be associated with gastrointestinal cancers. ${ }^{8}$ The sex difference in the association between BMI and non-sex-specific obesity-related cancers could partly be the result of a sex difference in distribution of fat. In general, obese men have more intra-abdominal fat compared with obese premenopausal women. Although the sex difference in intra-abdominal fat is less apparent in patients with T2D, the amount of intra-abdominal fat is probably still higher in men. ${ }^{11}$ Especially, this abdominal adiposity is associated with many metabolic abnormalities which may increases cancer risk. It might be that BMI was not accurate enough to represent the amount of abdominal fat especially in women with T2D. Using waist circumference as a marker of abdominal fat might have been more accurate.

In the present study, obese women had a $51 \%$ higher risk for ovarian, endometrial and postmenopausal breast cancer compared with lean women with T2D during follow-up. Only one previous study has described an association between BMI and sex-specific cancers in women with T2D. Miao Jonasson et al described a 39\% higher risk for postmenopausal breast cancer compared with lean women. ${ }^{8}$ The association of BMI with these types of cancer might be attributed to an increase in oestrogen production in adipose tissue in overweight and obese women with T2D. ${ }^{12}$ BMI and T2D itself have been found to be related to a higher risk of endometrial and breast cancer. ${ }^{3}$ Taken this together, this indicates that especially obese women with T2D are at risk for the development of endometrial cancer and postmenopausal breast cancer. On the other hand, some researchers have questioned the relation between T2D itself and breast cancer. They have suggested that the higher risk of postmenopausal breast cancer in women with T2D could be completely explained by residual confounding by overweight and not 
by having a problem with metabolic disturbance related to glucose control. ${ }^{13}$

In line with the results of the present study, Miao Jonasson et al could not find an association between BMI and prostate cancer in men with T2D. ${ }^{8}$ However, they included all prostate cancers, whereas only advanced prostate cancer is described by the World Cancer Research Fund to be related with BMI in the general population. ${ }^{5}$ Nevertheless, the International Agency for Research on Cancer Working Group has recently described that evidence for a preventive effect of the absence of excess body fat for fatal prostate cancer is limited. ${ }^{14}$ The present study adds to the literature that a relation between BMI and advanced prostate cancer is not present, at least not in men with T2D. Advanced prostate cancer should therefore be reconsidered as being obesity-related.

The strengths of the present study were the prospective design and the use of a large cohort of patients with T2D of which data on BMI were available. Some limitations of the present study should also be mentioned. First, the study population consisted only of patients with T2D who are treated in primary care. Patients in secondary care often have worse manifestations of T2D and might therefore have a higher cancer risk. Although this limitation implies that the generalisability of our results is limited to primary care, it is still representative for a large part of the T2D population due to the fact that the majority $(>85 \%)$ of the patients with T2D are treated in primary care in the Netherlands. ${ }^{15}$

Second, the clinical data and the data on medication use of the ZODIAC cohort were collected annually by practice nurses and GPs. The reliability of the data is therefore dependent on their accuracy. Third, data on BMI were missing for $9 \%$ of the patients. BMI values for these patients were estimated using multiple imputations. Fourth, the grouping of obesity-related cancers could be discussed. All different cancers were taken together as the number of total events would be too small when investigating each of the obesity-related cancers, separately. Nevertheless, separate analyses would have been better. Finally, the follow-up period was relatively short for cancer epidemiology and therefore the number of events is relatively small.

\section{CONCLUSIONS}

In men with T2D BMI is associated with the total group of obesity-related cancers and with non-sex-specific obesity-related cancers. However, BMI is not related to advanced prostate cancer. The present study provides an extra argument for questioning advanced prostate cancer being obesity-related, at least in men with T2D. In women, BMI is associated with the total group of obesity-related cancers and with ovarian, endometrial and postmenopausal breast cancer. BMI is not related to non-sex-specific obesity-related cancers in women with T2D.

\section{Author affiliations}

${ }^{1}$ Diabetes Centre, Isala, Zwolle, The Netherlands

${ }^{2}$ Langerhans Medical Research Group, Zwolle, The Netherlands

${ }^{3}$ Department of General Practice, University of Groningen and University Medical Center Groningen, Groningen, The Netherlands

${ }^{4}$ Department of Research, Netherlands Comprehensive Cancer Centre (IKNL), Utrecht, The Netherlands

${ }^{5}$ Department of Health Technology and Services Research, MIRA Institute for Biomedical Technology and Technical Medicine, Universiteit Twente, Enschede, The Netherlands

${ }^{6}$ Department of Cardiology, Radboud University Medical Center, Nijmegen, The Netherlands

${ }^{7}$ Department of Internal Medicine, Gelre hospital, Apeldoorn, The Netherlands ${ }^{8}$ Department of Internal Medicine, University of Groningen and University Medical Center Groningen, Groningen, The Netherlands

${ }^{9}$ Department of Internal Medicine, Isala, Zwolle, The Netherlands

Acknowledgements The authors thank the registration teams of the Comprehensive Cancer Centre the Netherlands for the collection of data for the Netherlands Cancer Registry and for the opportunity to link the Registry with the ZODIAC cohort.

Contributors SHH, DS, KJJHvH, KHG, AHEMM, GWDL, HJGB and NK designed the study. SHH and DS acquired the data. SHH, DS and KHG analysed the data. SHH, DS, KJJHH, KHG, SS, AHEMM, GWDL, HJGB and NK interpreted the data. SHH and DS drafted the manuscript. KJJHvH, KHG, SS, AHEMM, GWDL, HJGB and NK reviewed and edited the manuscript. All authors read and approved the final manuscript. SHH is the guarantor of this work and, as such, had full access to all the data in the study and takes responsibility for the integrity of the data and the accuracy of the data analysis.

Funding This study was supported by a research grant (grant number 836041017) of the research programme Good Use of Medication from the Netherlands Organization for Health Research and Development (ZonMw).

\section{Competing interests None declared.}

\section{Patient consent Obtained.}

Ethics approval This study approved by the Medical Ethics Committee Isala Zwolle, Zwolle, the Netherlands (METC reference number 130765). In the first years ofZODIAC, verbal informed consent was obtained from all patients and the consentwas documented in the patient's records. According to Dutch law, writteninformed consent was not necessary for this type of study in 1998. Nowadays, written informed consent is obtained. The linking of the ZODIAC cohort with theNetherlands Cancer Registry (NKR) was approved by both the medical ethicscommittee of the Isala as well as the NKR. The linking was performed by atrusted third party.

Provenance and peer review Not commissioned; externally peer reviewed. Data sharing statement № additional data are available.

Open Access This is an Open Access article distributed in accordance with the Creative Commons Attribution Non Commercial (CC BY-NC 4.0) license, which permits others to distribute, remix, adapt, build upon this work non-commercially, and license their derivative works on different terms, provided the original work is properly cited and the use is non-commercial. See: http://creativecommons.org/ licenses/by-nc/4.0/

(c) Article author(s) (or their employer(s) unless otherwise stated in the text of the article) 2018. All rights reserved. No commercial use is permitted unless otherwise expressly granted.

\section{REFERENCES}

1. Peters SA, Huxley RR, Woodward M. Diabetes as risk factor for incident coronary heart disease in women compared with men: a systematic review and meta-analysis of 64 cohorts including 858,507 individuals and 28,203 coronary events. Diabetologia 2014;57:1542-51.

2. Peters SA, Huxley RR, Woodward M. Diabetes as a risk factor for stroke in women compared with men: a systematic review and metaanalysis of 64 cohorts, including 775,385 individuals and 12,539 strokes. Lancet 2014;383:1973-80.

3. Giovannucci E, Harlan DM, Archer MC, et al. Diabetes and cancer: a consensus report. Diabetes Care 2010;33:1674-85. 
4. Johnson JA, Carstensen B, Witte D, et al. Diabetes and cancer (1): evaluating the temporal relationship between type 2 diabetes and cancer incidence. Diabetologia 2012;55:1607-18.

5. World Cancer Research Fund. Cancers linked with greater body fatness [Webpage] [Internet], 2015. http://www.wcrf.org/int/cancerfacts-figures/link-between-lifestyle-cancer-risk/cancers-linkedgreater-body-fatness (cited 23 Mar 2016).

6. Yamamoto-Honda R, Takahashi Y, Yoshida Y, et al. Body mass index and the risk of cancer incidence in patients with type 2 diabetes in Japan: Results from the National Center Diabetes Database. J Diabetes Investig 2016;7:908-14.

7. Peeters PJ, Bazelier MT, Leufkens HG, et al. The risk of colorectal cancer in patients with type 2 diabetes: associations with treatment stage and obesity. Diabetes Care 2015;38:495-502.

8. Miao Jonasson J, Cederholm J, Gudbjornsdottir S. Excess body weight and cancer risk in patients with type 2 diabetes who were registered in Swedish National Diabetes Register-register-based cohort study in Sweden. PLoS One 2014;9:e105868.

9. Ubink-Veltmaat LJ, Bilo HJ, Groenier KH, et al. Shared care with task delegation to nurses for type 2 diabetes: prospective observational study. Neth J Med 2005;63:103-10.
10. Bowker SL, Richardson K, Marra CA, et al. Risk of breast cancer after onset of type 2 diabetes: evidence of detection bias in postmenopausal women. Diabetes Care 2011;34:2542-4.

11. Wannamethee SG, Papacosta O, Lawlor DA, et al. Do women exhibit greater differences in established and novel risk factors between diabetes and non-diabetes than men? The British Regional Heart Study and British Women's Heart Health Study. Diabetologia 2012;55:80-7.

12. Gallagher EJ, LeRoith D. Obesity and Diabetes: The increased risk of cancer and cancer-related mortality. Physiol Rev 2015;95:727-48.

13. La Vecchia C, Giordano SH, Hortobagyi GN, et al. Overweight, obesity, diabetes, and risk of breast cancer: interlocking pieces of the puzzle. Oncologist 2011;16:726-9.

14. Lauby-Secretan B, Scoccianti C, Loomis D, et al. Body fatness and cancer--viewpoint of the IARC Working Group. N Engl J Med 2016;375:794-8.

15. InEen. Transparante ketenzorg diabetes mellitus, COPD en VRM rapportage zorggroepen over 2014, 2015. 